\title{
Lessons from adaptation of local knowledge and traditional practices for urban public spaces as an effective tool for Urban development in hot cities.
}

\author{
Poonam KATRE, Urban Designer, India
}

\begin{abstract}
Historically, Hot cities around India have always relied on urban public spaces for its sociocultural as well as economic activities. They showed a greater capacity to adopt and sustain over time. The reason seems to be lying under its tendency to evolve and accommodate temporality and sustain with its constancy. These urban public spaces were strongly bonded with religions and customs rooted in nature and inbuilt into societal norms, there by emphasizing greater ecological consciousness and protection.

But in the last century, globalization brought aesthetic \& grand spectacle as deciding criteria for planning and designing of the urban public spaces. The result is, energy consuming, deserted, inaccessible and underutilized public spaces over a longer period as opposed to its short-lived fame. Urbanization has given rise to the new narrative for these urban public spaces which evolved in to hybrid versions conceptualized from global practices. This pose a threat in terms of loss of civic life and decreasing social cultural flows in the city.

Cities with the highest temperature seems to be getting the worst of it, essentially due to two main reasons. First are the adopted global models being not responsive to the local context, failing to stay active over longer periods of time and second due to failure to reconceptualize our traditional practices and local knowledge associated with development of cities in to ongoing practices.

Previous study of historic Indian public spaces in hot cities, highlights their nature as being symbolic, functionalist, political, performative, and cultural and hence proving to be contextually sensitive. These urban public spaces were designed to be a platform extension of their everyday outdoor life. This everyday outdoor life in hot cities have taken a shape in to various manifestation of forms. And emphasized more on organic development of public spaces.

Now, the current system in India that is responsible for generating our urban public spaces are regulated and mandated by state and local guidelines such as, URDPFI guidelines etc. which only mentions about open spaces to be left per area per person or in terms of percentage or buildable area. Little to no consideration has been given to how that open space should be treated.

The solution can be found in adaptation and reconceptualizing of these local knowledge and traditional practices suitable to today's spatial context. But a greater consideration needs to be given to the modern-day applicability and checking its suitability.

With that consideration, the paper will try to analysis selective samples of urban public spaces before the industrialization in the hot cities depending upon the generic public places i.e., Access and linkage, Purpose and activities, comfort and image, sociability, (Project for public spaces), adaptability, Thermal comfort, User responsiveness. The results then will be tested to check its adaptability in present day context with the help of case study.
\end{abstract}




\section{Keywords}

Urban Public spaces, local knowledge, Hot cities, Bhopal

\section{Introduction}

Cities and Urban areas around the world are particularly sensitive about the climate change. Rising temperatures, extreme weather events like droughts and floods are setting out to be one of the defining issues of the early 21st century. They are greatly impacting urban life thereby affecting basic services like housing, health, public infrastructure and livelihood in the cities. From 1880 to 2012, the average global temperature increased by $0.85^{\circ} \mathrm{C}$, hence the $2 \mathrm{C}$ rise by 2050 is comparing the present day to what temperatures were in the "pre-industrial period. (Fifth Assessment Report, The UN Intergovernmental Panel on Climate Change (IPCC). In future Adaptation to climate change is integral to city development.

Most of the heat in urban areas are trapped due to UHI (Urban heat island) effect, contributed largely due to concretisation of city infrastructure, out of which around $10 \%-20 \%$ (variables) space belongs to public domain. As a result, temperature trapped in those urban public spaces relates directly to its usage and accessibility.

Modern Urban public spaces which are open to access have become increasingly unusable due to lack of measures taken during its Planning and designing. Cities with the highest temperature seems to be getting the worst of it, essentially due to two main reasons. First are the adopted global models being not responsive to the local context, failing to stay active over longer periods of time and second due to failure to reconceptualize our traditional practices and local knowledge associated with development of cities in to ongoing practices.

The paper will try to analysis selective samples of urban public spaces before the industrialization in the hot cities depending upon the generics of public places i.e., Access and linkage, Purpose and activities, comfort and image, sociability, (PPS 2000), adaptability, green and blue infrastructure, User responsiveness. The results then will be tested to check its adaptability in present day context with the help of case study.

\section{Defining Urban Public Spaces}

Urban public space shapes and is shaped by society-its relationships, priorities and its fears. (Contemporary Public Space, Part Two: Classification, Matthew Carmona). This defines how Urban Public spaces play major role in our perception towards city image and Quality of Public life. City infrastructure plays a major role in providing public the 'public life'. People create 'Public life' when they connect with each other in public spaces -streets, plazas, parks and city spaces between buildings. Public life is about the everyday activities that people take part in when they spend time with each other outside of their homes, workplaces and cars. (Ghel,2018)

Urban public spaces are binders to the fabric of cities private life. Calling the public together for all types of interactions. These were the main spaces for social, cultural, political and economic interaction in the cities such as, bazaar (market) street, chowks (Street junctions), stepwells, Courtyards, Chabutra (Threshold spaces). A place, where the practice of democracy, justice, equity and the interchange of opinions are at the basis of society. [A. Atkinson, 1992] 


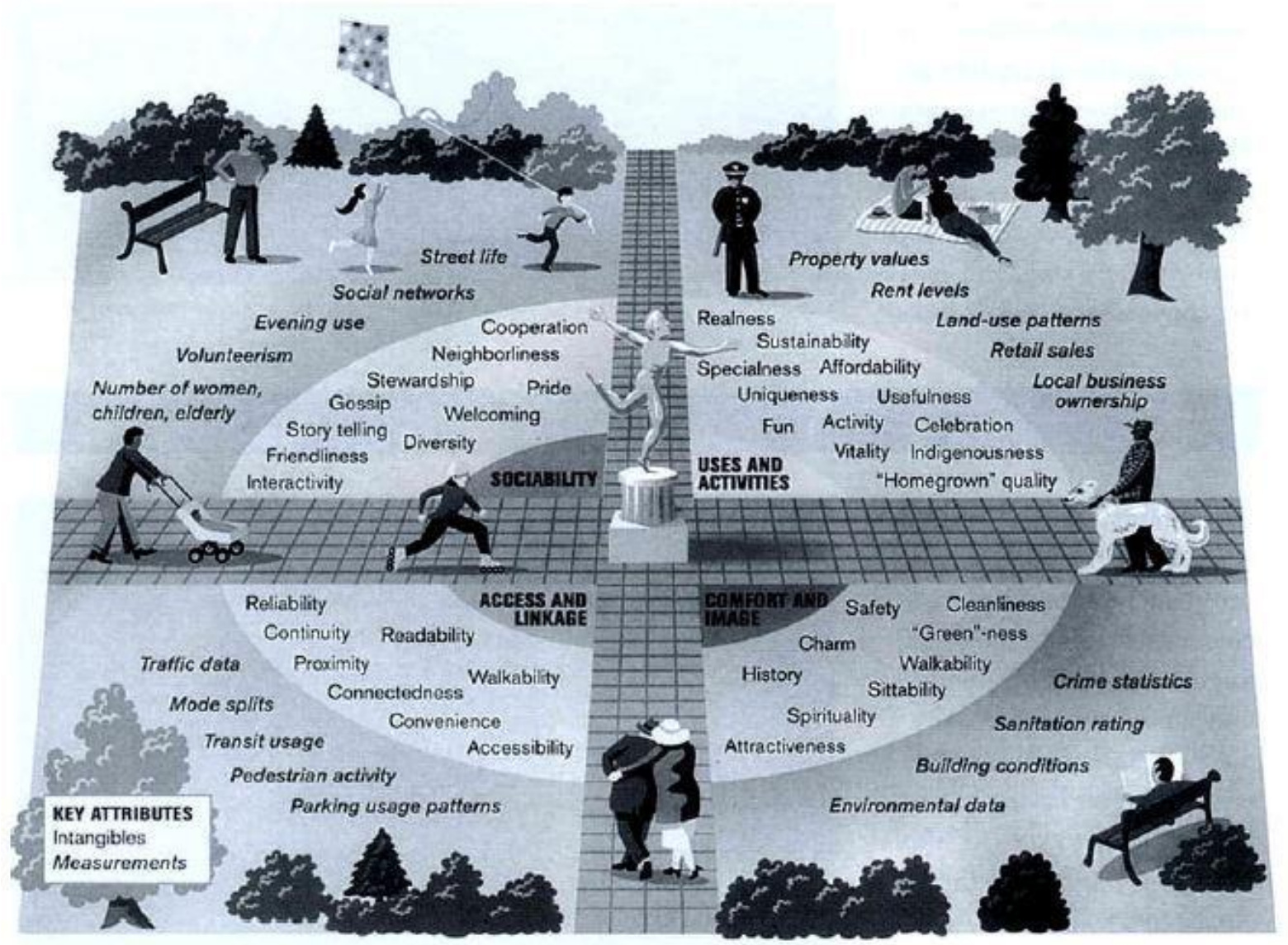

Figure 1. Four main characteristics of Urban public space according to PPS. Source: PPS, 2000

Each thriving and successful urban public space should be equipped with indicators which will help them become more attractive to people such as,

Access and linkage: Clear visual links, Free to access, connected to the surroundings, easy to navigate, interior visibility, edge treatment, universal accessibility, and pedestrian infrastructure all these indicators make up for good accessibility in public spaces.

Purpose and activities: Offering range of activities for relaxing, playing, walking, dancing, eating such as, sitting arrangements for individuals to communal gatherings, can become meaningful purpose to invite people into the space.

User responsiveness: Active Stakeholder participation from citizens, designers, planners, interest groups, government entities, non-profit organisations indicates good user responsiveness.

Comfort and image: Indicators such as, inviting place, adequate infrastructure, perception of safety, cleanliness, welcoming first impression to all genders and age groups, thermal comfort, well maintained, guarded, and availability of places to sit throughout day can create a sense of comfort and good image in public spaces.

Sociability: The public space which offers activities to various age groups and ethnic groups, comfort of interaction, sense of ownership indicates great sociability.

Adaptability: Offering a capacity of adapting to changing needs of the surrounding area and neighbourhood is of at most important. Indicators such as, upgradation of infrastructure, 24/7 
availability, scope to host cultural, performative, interactive, economic, social interactions can help make space flexible to adapt to changing requirements out of public space.

Thermal comfort: This is One of main criteria in current context to further development of public spaces. Indicators such as investment in good Green and Blue infrastructure, use of locally sourced materials can offer great thermal comfort in the public spaces.

Simply put Urban public spaces can be defined as 'Open Spaces' in the cities. Which are free to access and to use in the interest of both public and government. While, theoretically these urban public spaces can be defined as 'free to access, owned by the government, democratic open spaces. But in deeper perspective they are much more than that. Considering current urbanisation in the wake of globalisation and growing number of urban settlements gives a complex definition to these spaces. They are now characterised by varying ownerships and functionalities. Some are Public-private spaces managed by private bodies on lease by government. While some spaces are entirely private but reflects a pseudo image of being free to access.

\subsection{Urban Public spaces through time in India}

'Experience of public is experience of the city', Urban public spaces were always an important element of spatial urban fabric of Indian cities. These unique spatial identities depict their own sense of place. Essentially these spaces were developed as a functional necessity of the city hosting daily essential activities to annual grand gatherings either for political or religious purposes. These spaces were strongly engraved into city fabric due the constancy it offered as well as its quality of transformation according to needs of public. Relatable Human scale, visually grand but functionally apt, protected, participatory culture made these spaces socially dynamic. The reason being, deep rooted in its core is usage of Local Knowledge and traditional practices.

Before industrialisation (1870-1950) in India, it was during Mughal rule that formally designed public spaces were introduced in the form of the great Mughal gardens, water fountains for thermal comfort. Before that most of the public spaces were communal in nature. Either hosting a daily functional activity, take for example bazar streets of Delhi or sacred groves of Puducherry.
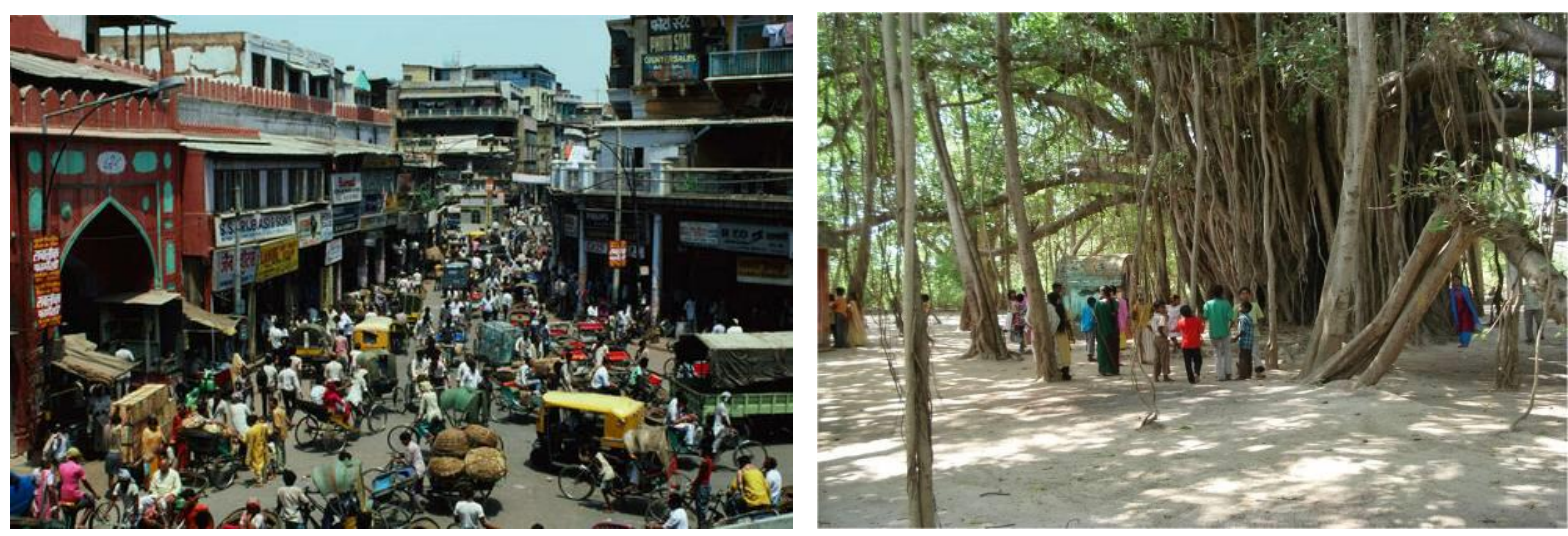

Figure 2 Sadar Bazar, Delhi Source: Tol,2014 and Sacred Groves of Puducherry. Source: enviscpreec, blog 

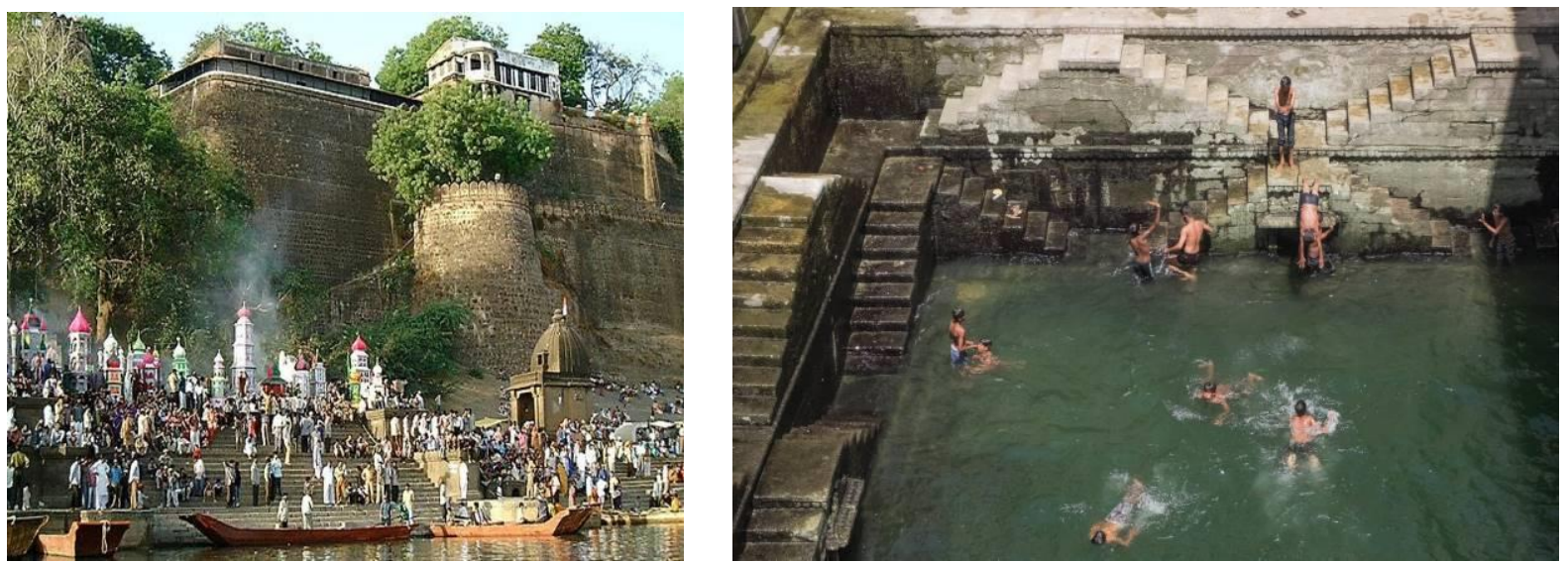

Figure 3 River Ghat, Maheshwar. Source: advenjo and Toorji ka Jhalara, Jodhpur. source: manvsglobe
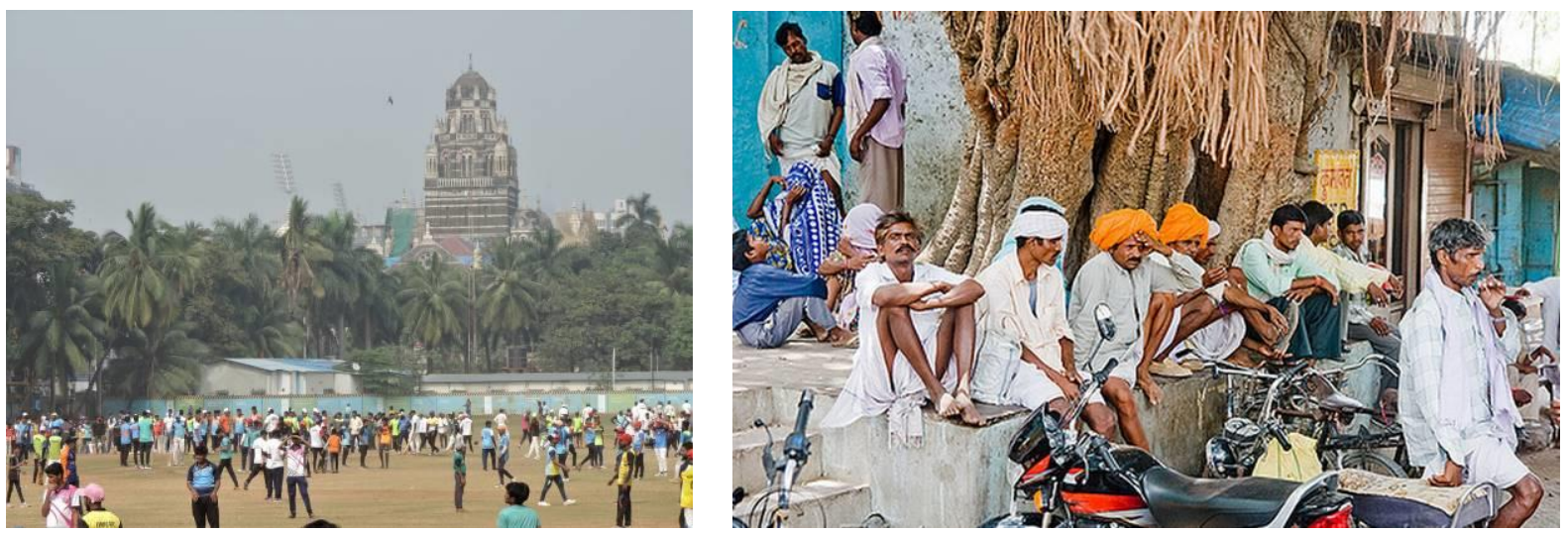

Figure 4 Oval Maidan, Mumbai and Gao chabutara

Commercial bazar streets and squares have been the age-old public domain in traditional urban landscape of Indian cities. Being the centre of most economic activities it also eventually hosted social and cultural interactions. similarly, Religious institution played huge role in providing secured space for the cities. Often equipped with sacred groves, temple tanks, bathing Ghats or step wells they established importance of green and blue infrastructure in the backdrop. The nature of most of these urban public spaces was essentially user centric and community oriented.

It was during industrialisation and around colonisation period that the concept of public parks and maidans were formally introduced in Indian city fabric. They eventually became centres for the major political gatherings \& events in Indian history.

\subsection{Current developments}

Today we need to look at urban public space not in relation to the state and its developments, but instead as a public space open to society at large. Regarding law, it is maybe nearer to the more seasoned idea of the "democratic space", in spite of the fact that how we perceive that today, most of the land is currently managed by the laws of property development. Which usually regulates entitled proprietor or an owner. Urban public space in India today have become a part of political aspirations and dominance producing unthoughtful developments. 
Indian law requires $15 \%$ of land to be dispensed for green space, the calculations are done on $\%$ per basic which clearly talks only about its calculative side and not about its nature of development. Eventually neighbourhoods keep on lacking public spaces. Indian urban areas have seen a considerable expansion in the interest for business and private property improvement, which has come about in most of public spaces being infringed onto or redeveloped for different purposes. The excess spaces are regularly overlooked and left to disintegrate, which deters the populace from utilizing them.

\section{Hot Climates, Cities and Public Spaces}

\subsection{Climate responsive infrastructure}

India is divided by two sublimates_tropical wet and dry climate and tropical monsoon climate. The wet and dry climatic regions, upper western and central part of India has few of the hottest cities around world. The average temperature rises above $45 \mathrm{c}$ during summers. "More than $60 \%$ of India has experienced significant warming during the 1951-2015 observed record. The rise in summer temperature is already more than one degree in the last 60 or so years," (Water and Climate Lab , (IIT)-Gandhinagar)

It has been observed that large parts of india have been experiencing frequent occurrences of hot days with very high temperatures as compared to pre industrialisation. These climatic conditions have made lasting impact on basic needs, health, agriculture and public infrastructure which inturn will affect various aspects of socio-cultural well being.

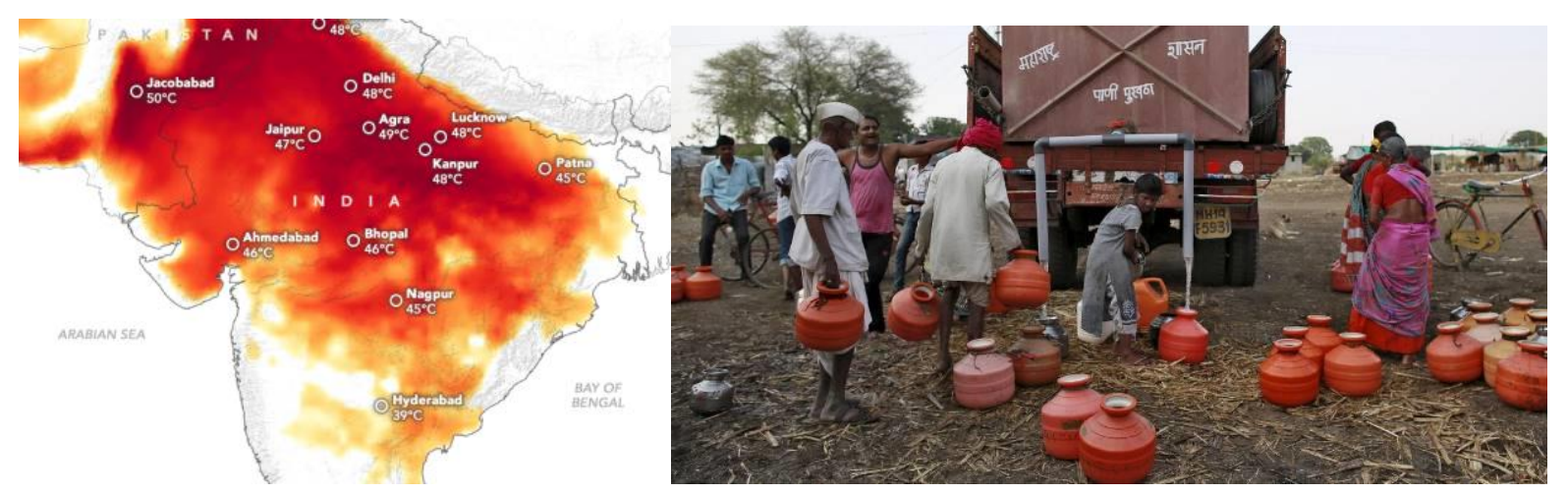

figure 5 Average temperature in hot cities during summers in India. Source: Quarts India

Hot cities around India have always relied on urban public spaces for its sociocultural as well as economic activities. They showed a greater capacity to adopt and sustain over time. The reason seems to be lying under its tendency to evolve and accommodate temporality and sustain with its constancy. These urban public spaces were strongly bonded with religions and customs rooted in nature and inbuilt into societal norms, there by emphasizing greater ecological consciousness and protection.

Previous study of historic Indian public spaces in hot cities, highlights their nature as being symbolic, functionalist, political, performative, and cultural and hence proving to be contextually sensitive. These urban public spaces were designed to be a platform extension of their everyday outdoor life. This everyday outdoor life in hot cities have taken a shape in to various manifestation of forms such as - public gardens, sacred groves, bathing Ghats, step wells and temple tanks which were provided a required comfort and escape from hot climate around. (sasidharan \& prosperi 2012). And emphasized more on organic development of public spaces.

Increasing number of cities with hot temperature, demands an urgent need for contextually sensitive development measures in order to protect the health and well-being of inhabitants as well as social 
function of public places in future sustainable cities. (sustainable development goals 3 and 11, United nations 2015).

Future usability of urban public spaces is likely to decrease in future without any measures towards adaptation to the increasing heat. Open public spaces will play important role in regulating and controlling urban climates. Their sociability and multifunctionality is directly related to demands out of it. The adaption measures to create thermal comfort and climate sensitive solutions will help transform these spaces into climate resilient developments.

\subsection{Challenges}

Cities hold centre position to effects of climate change. They are more vulnerable that the others and open spaces being an important part of city fabric makes it eventually making it vulnerable to extreme climatic conditions. They directly affect functioning capacity of public spaces, urban infrastructure, various social and cultural aspects related to its inhabitants.

As the one size fits all approach and heavy influence of western models are continuing to use for the designing new public spaces it is resulting in increased thermal discomfort and reducing down the life of public spaces.

\section{Case Example: Lower lake Bhopal}

Bhopal is an administrative capital of India. And currently one of the cities to be developed under smart city mission. Located in a central part of the country, it has dry summer semi-arid climate with highly erratic rainfall. The densely built-up areas of the city of Bhopal are regularly prone to urban overheating and increasing temperatures and heat waves during summers. The city holds multitudes of public spaces to fulfil various functions from sport activities, recreational activities, waterfront development, event spaces, Maidan's to development of pedestrian infrastructure in current smart city mission. To narrow down the research scope the study focuses on development of public spaces along the edge of lower lake only.
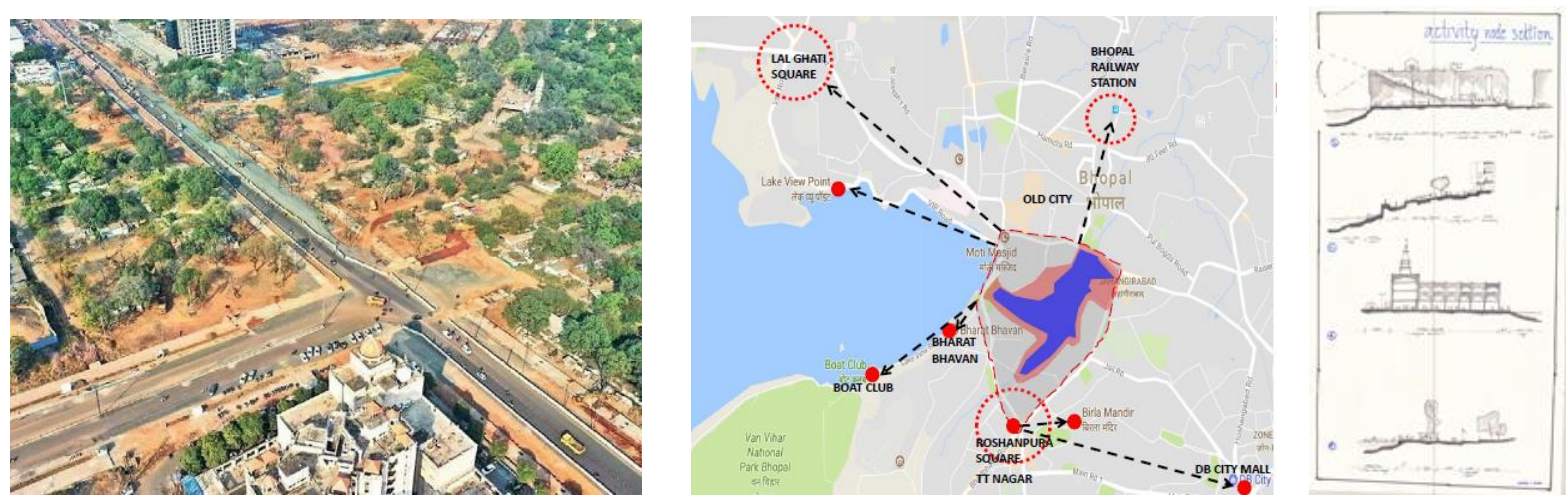

figure 6. Area under Smart city Bhopal and Lower lake surroundings. Source: Author

The city was created by king bhoj in 11st century. During his reign the region was going through severe drought cycles, upon which the king commanded the construction of upper and lower lake in the city. The lower lake today is source of livelihood for 250 washer men families who belongs to socio-economically 
weaker section. And BMC is the custodian of the lakes and holds the authority to control the development along the fringes of lake.

With the passage of time the city has witnessed a tremendous influx of urban development. Both the lakes being centrally located in the city has been affected by this increasing development pressure. As compared to upper lake, the lower lake was designed to manage overflow spillage from upper lake and hence was used for secondary activities like small fishing activity and as a (washer men) dhobi ghat. Many fishing and dhobi communities settled on the edge around the lake. But it started deuteriation of lake due to located within urban catchment, increased inflow of silt, untreated sewage being dumped in to water, use of chemicals to wash the cloths, nutrients and pesticides from nearby agricultural land was flowing into the lake with rainwater. Many programmes have been implemented to improvise the condition of the lake. One of major step was 'Bhoj wetlands' project. Almost $70 \%$ of fringe along the lower lake corridor was developed under bhoj wetlands project.

The study of lower lake edge gives both examples of good practise and bad practise for the development of urban public spaces in the context of hot climate. The lake offers much needed thermal comfort in the hot and dry climate of Bhopal. Half the portion of lake which is located around recent development is designed by implementation of integrated conservation and management plan into series of parks and recreational activities. While half the edge located towards old city area is still inhabited by communities with close connection to the lake edge. 


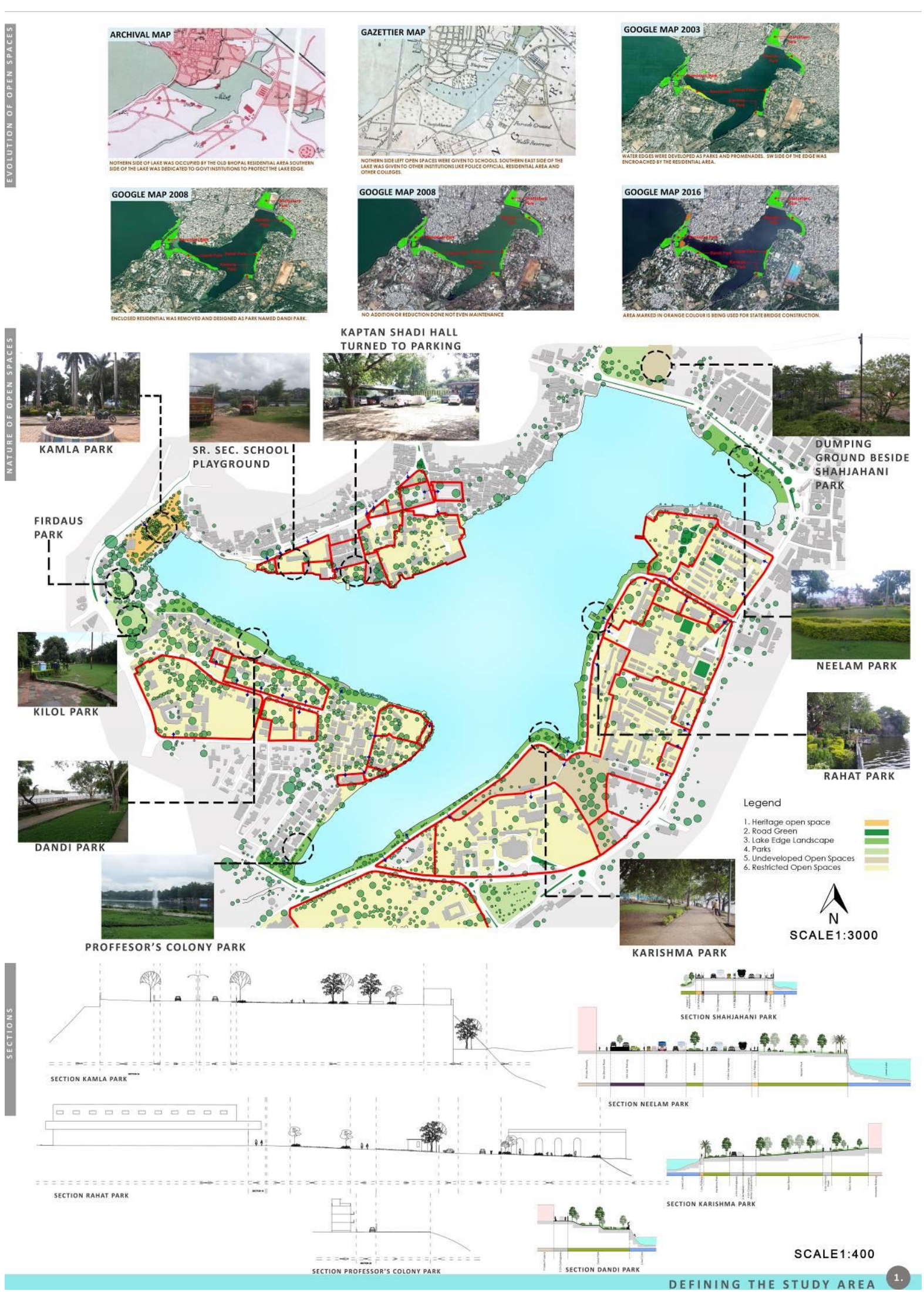

figure 7 Study of development along lower lake edge. Source: Author 
Located on the northern part of lower lake is kamlapati park. The park was designed on the embankment of upper lake by rani kamlapati. It acts as a transitional space from busy highway to recreational activity. The enclosure quality and constant surveillance through exhibition centre offers the park to attract many passers-by to hang around.

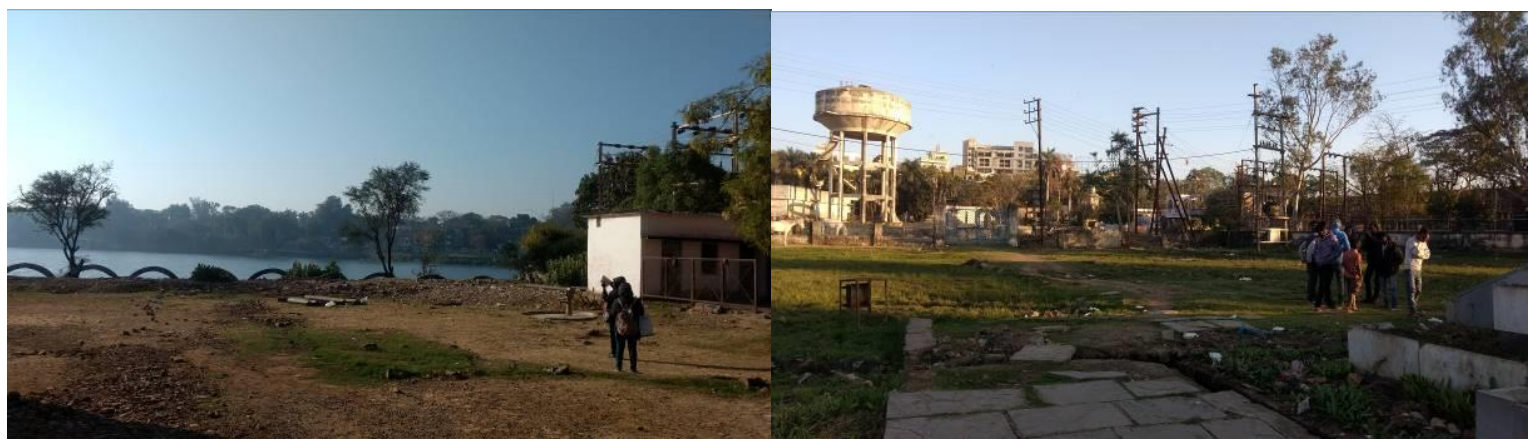

figure 8 Deserted parks along the lake edge. Source: Author

Towards new developed edge, Except for kamala park, rest of the developed parks during bhoj wetland project like Dandi park, Rahat park, shahjahani park, Karishma park and Neelam park are facing issues like poor accessibility, lack of maintenance and security and lack of green infrastructure.

Firdaus park specially designed for women's is one of the least used public space due to lack of visibility and poor accessibility to the park. The threshold of the park is male dominant due to presence of informal eateries and accounts to be very unsafe for the women achieve the exact opposite from its purpose.

Aquamarine park designed with water show is un operational due to lack of maintenance and failure to gather people's attention. The cost of operating the park was much higher than the revenue it collected. The park was attraction at the launch for the water works but could not sustain once its condition started deteriorating and the curiosity died. Design of the park was infused from water shows overseas but it failed to adopt according to its contextual requirements.
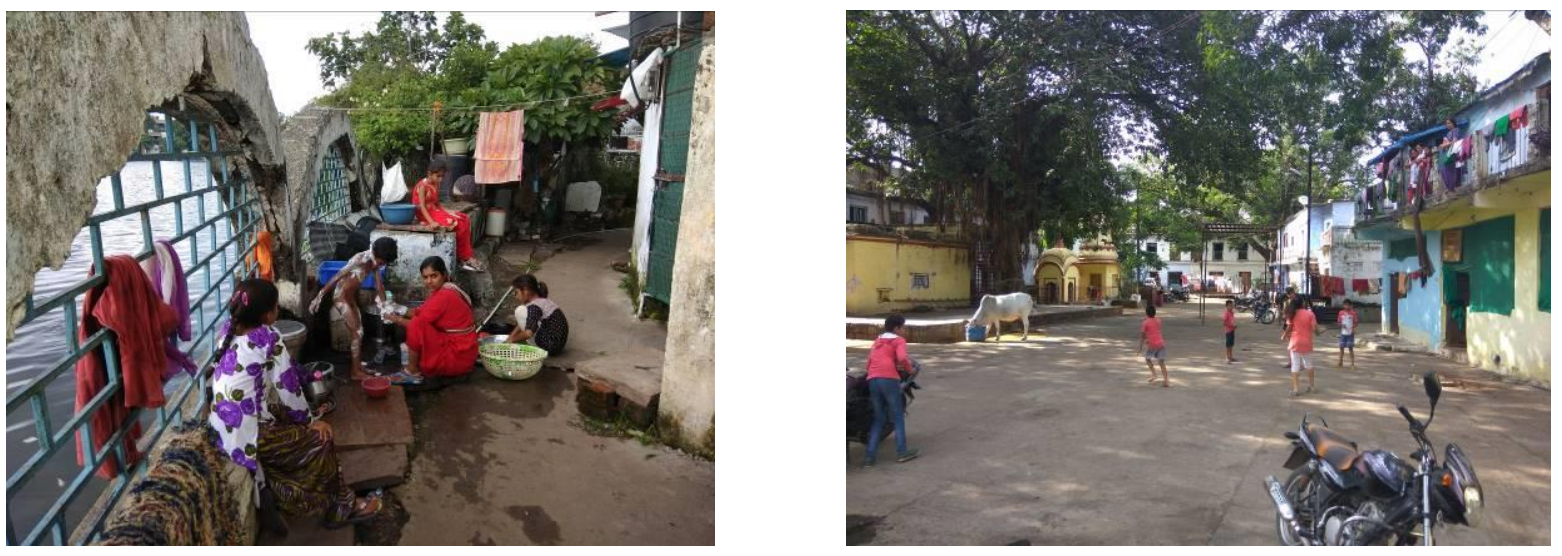

figure 9 Very active lake edges towards older city area. Source: Author

On the other hand, the lake edge towards old city is much more active and used to its potential. The reason seems to be lying under easy access to lake edge and its close connection to neighbouring communities. The livelihood of the neighbouring fisherman and washer man community is directly depended upon lake which generate range of activities within shared places. These shared public spaces have been gathering spots for people of all the genders and are open to access throughout day. They are well protected due to presence of religious institutions giving it a sense of safety as well. 


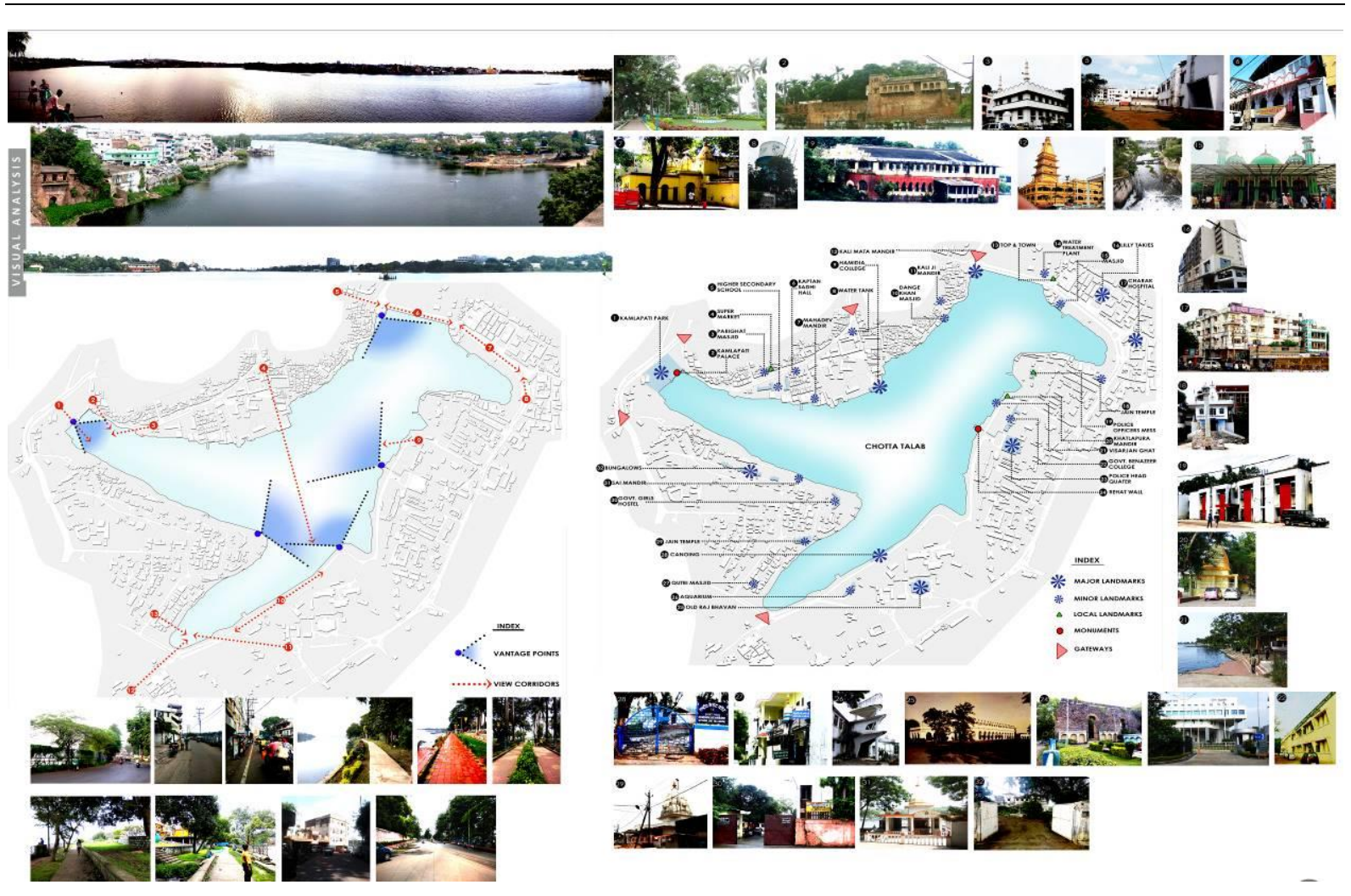

figure 10 Visual analysis of lower lake, Bhopal City. Source: Author

Most of these religious institutions have scared groves and congregational space in their vicinity. The sacred groves provide much needed thermal comfort and shaded places for gatherings and events throughout the year. This kind of public places successfully provides opportunity in conducting and hosting various kind of social and cultural interaction for the communities. The close connection of residential area ensures natural surveillance over these spaces.

Most of these public spaces have been developed organically on need basis. They emerged as an extension to people's everyday life or in the form of threshold spaces. They have mixture of both formal and informal activities. Essentially, they naturally involve all the stakeholders to participate in its functioning making it user centric.

It's a clear observation that recently developed lake edge fails to attract public inside and is underutilised as compared to its counterpart on the other side towards older area which has close connection to the communities next to it. These spaces were developed through local knowledge and with traditional practices since last few centuries. They have been able to function consistently due to its context sensitive design and have been able to sustain in the hot climate of Bhopal city.

\section{Conclusion}

It may be concluded that, need for the contextually sensitive development of urban public spaces in hot cities is closely related to its functioning capacity. The study has shown the use of local knowledge and traditional practises, adopting transdisciplinary solution-oriented approaches and need of the hour. A closer association between climate data relevant decisions and traditional knowledge system can become the much-needed solution for the developments. User centric bottom to top approach is much favoured. The solution can be found in adaptation and reconceptualizing of these local knowledge and traditional 
practices suitable to today's spatial context. But a greater consideration needs to be given to the modernday applicability and checking its suitability. It is necessary to find opportunities to enhance green and blue infrastructure into the urban public spaces. And to identify requisite adaption measures to maintain full functionality with the help of transdisciplinary approach.

\section{References}

Foshag k., Aeschbach N., Hofle B., winkler R., Siegmund A., and Aeschbach W.(2020) 'Viability of public spaces in cities under increasing heat: A transdisciplinary approach', ScienceDirect, volume 59,Available at: https://www.sciencedirect.com/science/article/pii/S221067072030202X (Accessed 16 November 2020)

Sasidharan Priya, Prosperi David .C., Dichotomy of Urban Public Spaces, 48th ISOCARP Congress 2012

United Nations Report (2013), 'Climate change 2013_the physical science basis',30(2) [online]

Atkinson,A. (1992) "The Urban Bioregion as Sustainable Development Paradigm", Third World Planning Review, Vol.14, No.4

Carmona, M. (2003), Public spaces, the dimention of urban design, Oxford,Oxford architectural press.

Project for Public Spaces, (2005), Project for Public Spaces What Makes a Place Great, Available at: https://www.pps.org/article/grplacefeat (Accessed: 22nov2020)

Quartz India, ghosh s.,(2020), India's hot climate got hotter in the past decade, Available at: https://qz.com/india/1819028/indias-hot-climate-got-hotter-in-the-past-decade/ (Accessed: 22 Nov 2020)

Ali Madanipour, "Public and private spaces of the city", (2003), Routledge, Taylor \& Francis Group.

Carmona, M. and De Magalhaes, C. (2006) Public space management-present and potential. Journal of Environmental Planning and Management, pp. 75-99.

Carmona, M., De Magalhaes, C. and Hammond, L. (2008) Public Space, The Management Dimension Routledge, London

C. Adler, G. Hirsch Hadorn, T. Breu, U. Wiesmann, C. PohIConceptualizing the transfer of knowledge across cases in transdisciplinary research

J. Gehl, (2011), Life between buildings: Using public space, Island press (2011), Google Scholar 